\title{
PELATIHAN PENGUASAAN MENGETIK CEPAT 1O JARI DENGAN METODE DRILL DI SMK NEGERI 5 BANDAR LAMPUNG
}

\author{
Suripto$^{1}$, Supriyanto², Eri Maryani3 \\ 1,2,3Program Studi Ilmu Administrasi Bisnis, Fakultas Ilmu Sosial dan Ilmu Politik, \\ Universitas Lampung \\ ${ }^{1}$ E-mail address: riptounila@gmail.com; 2 E-mail address: \\ supriyanto.1989@fisip.unila.ac.id; 3E-mail address: eri.maryani@fisip.unila.ac.id
}

\begin{abstract}
The purpose of this service is to improve mastery skills and skills in fast typing for students of SMKN 5 Bandar Lampung. For the problems faced by students, namely how to apply fast typing using the drill method in order to complete work related to typing, which can be completed quickly, correctly and on time. The long-term target to be achieved in this activity is closely related to the problem of using the drill method using the typing test application which covers a very wide range for students, teachers and secretaries which leads to improving their performance. The steps taken to master fast typing are through coaching and improving fast typing exercises by using several typing test applications using the drill method. The output of this activity is the scientific article Shinta 4 Lancang Kuning University, activity videos, and service profiles published at the University of Lampung dedication seminar. The methods used are interesting discussions, lectures and practicals, about the drill method in the typing test. By holding fast typing training with the Drill method, it is intended for students of SMKN 5 Bandar Lampung, to be able to further improve their mastery and skills in fast typing.
\end{abstract}

Keywords: Drill Method, 10 Finger Typing, SMKN 5

\begin{abstract}
Abstrak
Tujuan pengabdian ini adalah untuk meningkatkan kemampuan menguasai dan keterampilan dalam mengetik cepat bagi para para siswa-siswi SMKN 5 Bandar Lampung. Untuk permasalahan yang dihadapi oleh pelajar yaitu Bagaimana mengaplikasikan mengetik cepat dengan menggunakan metode drill agar dapat menyelesaikan pekerjaan yang berkaitan dengan ketik mengetik dapat diselesaikan dengan cepat, benar dan tepat waktu. Target jangka panjang yang akan dicapai dalam Kegiatan ini berkaitan erat dengan masalah pemanfaatan metode drill dengan menggunakan aplikasi typing test yang mencangkup jangkauannya sangat luas bagi pelajar, guru dan sekretaris yang mengarah pada peningkatan kinerjanya. Langkah yang ditempuh untuk penguasaan mengetik cepat tersebut adalah melalui
\end{abstract}


pembinaan dan peningkatan latihan mengetik cepat dengan menggunakan beberapa aplikasi typing test dengan menggunakan metode drill. Luaran dari kegiatan ini adalah artikel ilmiah shinta 4 Universitas Lancang Kuning, video kegiatan, dan profil hasil pengabdian yang dipublikasikan pada seminar hasil pengabdian Universitas Lampung. Metode yang digunakan adalah diskusi, ceramah dan praktikum yang menarik, tentang metode drill dalam typing test. Dengan diadakannya Pelatihan mengetik cepat dengan metode Drill ini ditujukan untuk para siswa-siswi SMKN 5 Bandar Lampung, untuk bisa lebih meningkatkan kemampuan menguasai dan keterampilan dalam mengetik cepat.

Kata kunci: Metode Drill, Mengetik 10 Jari, SMKN 5

\section{PENDAHULUAN}

Perkembangan infrastruktur teknologi informasi global telah mengubah pola dan cara kegiatan bisnis, industri, perdagangan, dan pemerintahan. Perkembangan ekonomi berbasis ilmu pengetahuan dan informasi telah menjadi paradigma global yang dominan. Didalam masyarakat khususnya sebagai pengguna komputer untuk itu kemampuan untuk terlibat secara efektif dalam revolusi jaringan informasi akan menentukan masa depan kesejahteraan bangsa dan dunia pendidikan (Fadilla Oktaviana \& Ida Nuraida, 2021), (Suntoro, 2020), (Permata et al., 2021), (. et al., 2021), (Erpidawati \& Novelti, 2021), (Khoiriyah \& Puspasari, 2021) .

Namun, hal ini bukanlah fakta yang buruk bagi dunia pendidikan. Hal ini semakin jelas terlihat ketika banyak instansi pendidikan yang mulai memanfaatkan teknologi hampir di

berbagai daerah di Indonesia. Instansi tersebut memanfaatkan teknologi yang disebut dengan metode Drill agar para siswa-siswi menguasai materi yang sangat sedang diajarkan lebih baik (Junaidi et al., 2020), (Tjahjono, 2016), (Sesunan et al., 2021), (Anita Desiani, 2020).

Belum meratanya kualitas SiswaSiswi dalam menguasai mengetik dalam pelajaran mengetik cepat dan berbagai permasalahan diatas, menjadikan proses pembelajaran yang dilakukan lewat internet tersebut biasanya masih belum maksimal. Olehkarena itu dengan adanya pelatihan mengetik cepat untuk peningkatan penguasaan mengetik cepat di SMK Negeri 5 Bandar Lampung menjadi alternatif dalam teknik belajar mengajar yang berbasis metode Drill di mana metode ini digunakan untuk mencapai sasaran-sasaran dan mendukung konsep pembelajaran yang 
modern (Media et al., 2017), (Ninghardjanti \& Yuwantiningsih, 2018). Selain itu ketersediaan metode Drill dalam instansi pendidikan akan membantu baik guru dan murid dapat saling membantu dan mempercepat dalam menyelesaikan pekerjaan yang satu sama lain sehingga dapat meningkatkan keuntungan bagi kedua belah pihaak. Pada pengabdian ini nantinya akan melibatkan \pm 59 siswasiswi SMKN 5 Bandar Lampung yang ikut dalam pelatihan ini.

\section{METODE}

\section{Metode}

Metode pelaksanaan kegiatan pengabdian yang akan dilaksanakan untuk mengatasi permasalahan adalah berikut ini.

1. Metode Ceramah

Metode ceramah merupakan metode yang diberikan kepada khalayak sasaran dengan tujuan untuk memberikan pengeprodukan dan pemahamanpemahaman pada khalayak sasaran. Ceramah yang diberikan berisi seputar pengembangan literasi keuangan produk melalui berbagai metode pengelolahan dan diadakan pelatihan dalam

mengembangkan promosi produk.

2. Metode Diskusi

Metode ini digunakan untuk mengetahui sejauh mana pengetahuan peserta pelatihan terhadap materi yang telah dijelaskan.

3. Metode Praktikum Pendampingan Dalam metode Praktikum pendampingan siswa-siswa dilatih dalam mengerjakan ujian pretest dan post test melalui aplikasi typing test.

\section{Kerangka Pemecahan Masalah}

Adapun kerangka pemecahan masalah dalam Pelatihan Penguasaan Mengetik Cepat 10 Jari Dengan Metode Drill Di SMK Negeri 5 Bandar Lampung dapat dilihat pada gambar dibawah ini.

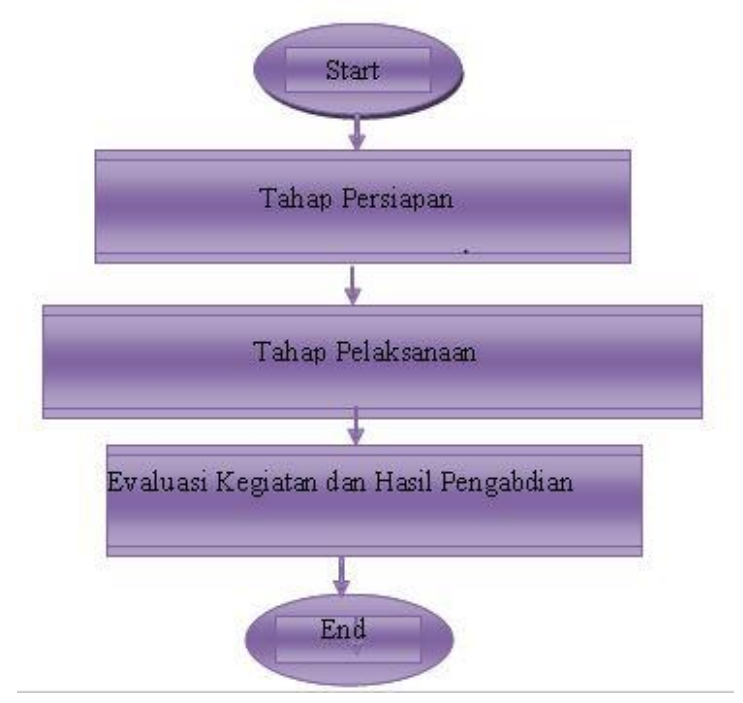

Gambar 1 Kerangka Pemecahan Masalah 


\section{Realisasi Pemecahan Masalah}

Untuk memecahan masalah dalam pencapaian memberikan kemampuan dalam mengetik cepat bagi siswa-siswi SMK Negeri 5 Bandar Lampung maka perlu diadakannya pelatihan.

Dalam kegiatan pelatihan ini peserta diberikan penjelasan mengenai mengetik cepat dengan menggunkan metode drill. Dalam pelaksanaan pelatihan ini akan melibatkan 2 (dua) orang dosen dan dibantu oleh 1 (satu) orang mahasiswa, hal ini dilakukan dengan tujuan agar kegiatan pelatihan ini mempunyai manfaat yang benar-benar dapat dirasakan oleh peserta pelatihan karena segala kesulitan-kesulitan peserta selama mengikuti pelatihan akan dapat diatasi dan peserta akan mendapatkan bimbingan yang optimal.

\section{HASIL DAN PEMBAHASAN}

\section{Hasil}

Kegiatan pelatihan ini diikuti oleh Siswa dan Guru SMKN 5 Bandar Lampung yang berjumlah 59 orang (absensi peserta terlampir). Untuk mengetahui pemahaman awal peserta tentang Pelatihan Penguasaan Mengetik Cepat 10 Jari dengan Metode Drill dan pola kolaborasi antar seluruh peserta yang terlibat dalam Pelatihan Penguasaan Mengetik Cepat 10 Jari dengan Metode Drill. Dikalangan Siswa-
Siswi dan Guru Jurusan Multimedia dilakukan dengan menggunakan pre-test yang berbentuk Praktikum Typing Test. Praktikum pre-test dikerjakan selama 30 puluh menit (soal pre-test terlampir). Materi pre-test merupakan rangkuman dari materi yang akan disampaikan dalam pelatihan. Kriteria hasil pre-test yang digunakan adalah sebagai berikut: (hasil pre-test dapat dilihat pada tabel 1).

a. Nilai $\mathrm{o}-50 \quad$ : Belum memahami

b. Nilai 51-75 : Cukup memahami

c. Nilai 76-100 : Sangat memahami

Berdasarkan hasil pre-test pada tabel 1 diketahui bahwa rata-rata tingkat pemahaman awal peserta adalah 59,83\%. Hal ini berarti peserta berada dalam kriteria Cukup memahami Penguasaan Mengetik Cepat 10 Jari dengan Metode Drill dan pola kolaborasi antar peserta yang terlibat dalam pelatihan ini. Seluruh peserta masuk dalam kriteria belum memahami Penguasaan Mengetik Cepat 10 Jari dengan Metode Drill.

Tabel 1. Hasil Pre-test Pemahaman Awal Peserta

\begin{tabular}{|c|c|c|c|}
\hline & & Tingkat \\
N & Nama & Jumla & Pemaham \\
& & heserta & an Awal \\
& & Skor & Peserta \\
& & $(\%)$ \\
\hline
\end{tabular}




\begin{tabular}{|c|c|c|c|c|c|c|c|}
\hline \multirow[t]{2}{*}{1} & $\begin{array}{c}\text { Aditya } \\
\text { Hari }\end{array}$ & \multirow[t]{2}{*}{67} & \multirow[t]{2}{*}{53,16} & 15 & $\begin{array}{l}\text { Balqis } \\
\text { Baity }\end{array}$ & 60 & 59,37 \\
\hline & Nugroho & & & \multirow{2}{*}{16} & Callysta & \multirow{2}{*}{53} & \multirow{2}{*}{67,21} \\
\hline \multirow[b]{2}{*}{2} & Ahmad & \multirow[b]{2}{*}{56} & \multirow[b]{2}{*}{63,61} & & Fania & & \\
\hline & $\begin{array}{c}\text { Merdi } \\
\text { Saputra }\end{array}$ & & & 17 & $\begin{array}{l}\text { Cinta } \\
\text { Bella }\end{array}$ & 60 & 59,37 \\
\hline 3 & $\begin{array}{l}\text { Ahmad } \\
\text { Rizky }\end{array}$ & 69 & 51,62 & \multirow{2}{*}{18} & $\begin{array}{c}\text { Claudia } \\
\text { Melah }\end{array}$ & \multirow{2}{*}{56} & \multirow{2}{*}{63,61} \\
\hline \multirow[t]{2}{*}{4} & $\begin{array}{c}\text { Ahmad } \\
\text { Sukry }\end{array}$ & \multirow[t]{2}{*}{51} & \multirow[t]{2}{*}{69,84} & & $\begin{array}{c}\text { Situmoran } \\
\mathrm{g}\end{array}$ & & \\
\hline & Pratama & & & 19 & Damar B & 68 & 52,38 \\
\hline \multirow{3}{*}{5} & $\begin{array}{c}\text { Ajeng } \\
\text { Mustika }\end{array}$ & \multirow{3}{*}{54} & \multirow{3}{*}{65,96} & 20 & $\begin{array}{l}\text { Darmawa } \\
\text { n Febrio H }\end{array}$ & 61 & 58,39 \\
\hline & Ayu & & & 21 & Deni Adi P & 57 & 62,49 \\
\hline & Azzahra & & & \multirow{2}{*}{22} & Dera & \multirow{2}{*}{60} & \multirow{2}{*}{59,37} \\
\hline \multirow{3}{*}{6} & Al-Halim & \multirow{3}{*}{54} & \multirow{3}{*}{65,96} & & Adelia & & \\
\hline & Nuor & & & 23 & Erin Togi & 44 & 80,95 \\
\hline & Wijaya & & & \multirow{3}{*}{24} & Erland & \multirow{3}{*}{60} & \\
\hline 7 & Aloysius A & 87 & 40,94 & & Adha & & 59,37 \\
\hline 8 & Alvian & 55 & 6476 & & Sharendra & & \\
\hline & Jalvano & J & & & Fadhel & 60 & \\
\hline 9 & Amara F & 58 & 61,41 & 25 & Akbar A & 00 & 52,30 \\
\hline 10 & Ana $S$ & 57 & 62,49 & 8 & Fara & & \\
\hline 11 & Ari & & & 20 & Nadila & 55 & 04,70 \\
\hline & Setiawan & & & & Fitri & & \\
\hline 10 & Aunea & 65 & {$[180$} & 27 & Noviana $\mathrm{F}$ & 57 & 02,49 \\
\hline & Shania & 5 & 54,00 & & Flora Nita & & \\
\hline & Bagas & & & 28 & Charda & 54 & 65,96 \\
\hline 13 & $\begin{array}{c}\text { Hermawa } \\
\text { n }\end{array}$ & 61 & 58,39 & 29 & $\begin{array}{l}\text { Habib } \\
\text { Raihan }\end{array}$ & 59 & 60,37 \\
\hline 11 & Bagus Leo & 67 & 5016 & & Delu & & \\
\hline 14 & Putra & 07 & 53,10 & 30 & Intana D & 67 & 53,16 \\
\hline
\end{tabular}




\begin{tabular}{|c|c|c|c|c|c|c|c|}
\hline \multirow[t]{2}{*}{31} & $\begin{array}{c}\text { Irma } \\
\text { Amelia }\end{array}$ & 62 & \multirow[t]{2}{*}{57,45} & 45 & $\begin{array}{l}\text { Niken } \\
\text { Meila }\end{array}$ & 59 & 60,37 \\
\hline & Novianti & & & \multirow{2}{*}{46} & Nur Salsa & \multirow[b]{2}{*}{54} & \multirow{2}{*}{65,96} \\
\hline \multirow{2}{*}{32} & Kayla & & \multirow{2}{*}{60,37} & & Bila & & \\
\hline & Sofya & 59 & & \multirow{3}{*}{47} & Rahmat & \multirow[b]{3}{*}{62} & \multirow{3}{*}{57,45} \\
\hline 33 & Kevin & 60 & 56,54 & & Kurniawa & & \\
\hline \multirow[b]{2}{*}{34} & Kevin & & \multirow{2}{*}{53,16} & & Hutasuhut & & \\
\hline & Chandra & 67 & & 48 & Raihan A & 63 & 56,54 \\
\hline \multirow{3}{*}{35} & Khadijah & & \multirow{3}{*}{67,21} & \multirow{3}{*}{49} & Raihan & & \multirow{3}{*}{69,84} \\
\hline & Amelia & & & & Bagus & & \\
\hline & Monica & 53 & & & Cahyani & 51 & \\
\hline \multirow{2}{*}{36} & M. Arif & & \multirow{2}{*}{58,39} & \multirow{3}{*}{50} & Rendy & & \\
\hline & Chandra & 61 & & & Hardiansy & & 61,41 \\
\hline \multirow{2}{*}{37} & M. Iqbal & & \multirow{2}{*}{60,37} & & ah & 58 & \\
\hline & Ryanisra & 59 & & \multirow{2}{*}{51} & Silpana & & -180 \\
\hline \multirow{2}{*}{38} & M.Rizki & & \multirow{2}{*}{41,91} & & Herman & 65 & 54,00 \\
\hline & Reza & 85 & & 5 & Siti & & 7124 \\
\hline \multirow{2}{*}{39} & Maurich & & \multirow{2}{*}{56,54} & & Fatimah & 50 & ד \\
\hline & Johan & 63 & & & $\begin{array}{l}\text { Siva } \\
\end{array}$ & & -16 \\
\hline \multirow{2}{*}{40} & Melisa Tri & & \multirow{2}{*}{62,49} & 53 & Cahya S & 69 & $3,0<$ \\
\hline & Cahyani & 57 & & 51 & Taufik & & 6007 \\
\hline \multirow{2}{*}{41} & Muhamaa & & 7960 & 54 & Hidayat & 59 & נכ, \\
\hline & d Al Fikri & 49 & 12,09 & 55 & Urfatul & 61 & 58,39 \\
\hline & Muhamm & & & & Verdian & & \\
\hline $4=$ & ad Aldi F & 61 & 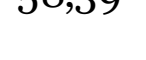 & 56 & Rachnada & & 50,89 \\
\hline & Muhamm & & & & ni & 70 & \\
\hline 43 & ad Gilang & & 54,80 & 57 & Veri Fadli & 59 & 60,37 \\
\hline & Priadinata & 65 & & & Vricila & & \\
\hline & Muhamm & & & 50 & Agatha & 49 & 12,09 \\
\hline 44 & ad Rafi & & 53,16 & & Yusril & & \\
\hline & Hakim & 67 & & 59 & Nurrizki & & 60,37 \\
\hline & & & & & Firdaus & 59 & \\
\hline
\end{tabular}




\begin{tabular}{|c|c|c|c|} 
& Jumlah & 3562 & 3530,14 \\
\hline & & $\begin{array}{r}\text { Rata- } \\
\text { Rata }\end{array}$ & $59,83 \%$ \\
\hline
\end{tabular}

Sumber : Hasil Pre-Test

\section{Pembahasan}

Dalam rangka mengetahui pemahaman akhir peserta tentang Penguasaan Mengetik Cepat 10 Jari dengan Metode Drill dan pola kolaborasi antar aktor yang terlibat dalam pelatihan ini dilakukan dengan menggunakan posttest yang berbentuk Ujian Praktikum Typing Test menggunakan metode drill. Ujian praktikum post-test yang diberikan sama dengan soal pre-test dengan penambahan waktu lebih banyak tujuan untuk mengetahui dampak dari pemberian materi selama pelatihan dan mengetahui progress peserta setelah pelatihan. Kriteria post-test yang digunakan sama dengan kriteria pre-test. Pemberian materi dilakukan secara tutorial (ceramah) yang dilanjutkan dengan dialog (tanya jawab) antara peserta dengan pemateri(Suripto, 2020) .
a. Nilai o-50 : Belum memahami
b. Nilai 51-75 : Cukup memahami
c. Nilai 76 - 100: Sangat memahami Proses pemberian materi diakhiri dengan diskusi, simulasi, dan

pembahasan contoh-contoh kasus. Hasil post-test dapat dilihat pada tabel 2.

Tabel 2. Hasil Pos-test Peserta

\begin{tabular}{|c|c|c|c|}
\hline $\begin{array}{c}\text { N } \\
\text { o }\end{array}$ & $\begin{array}{c}\text { Nama } \\
\text { Peserta }\end{array}$ & $\begin{array}{c}\text { Jumlah } \\
\text { Skor } \\
\text { Sebelu } \\
\text { m }\end{array}$ & $\begin{array}{c}\text { Jumlah } \\
\text { Skor } \\
\text { Sesuda } \\
\text { h }\end{array}$ \\
\hline 1 & $\begin{array}{c}\text { Aditya Hari } \\
\text { Nugroho }\end{array}$ & 67 & 90 \\
\hline 2 & $\begin{array}{c}\text { Ahmad } \\
\text { Merdi } \\
\text { Saputra }\end{array}$ & 56 & 81 \\
\hline 3 & $\begin{array}{c}\text { Ahmad } \\
\text { Rizky }\end{array}$ & 69 & 93 \\
\hline 4 & $\begin{array}{c}\text { Ahmad } \\
\text { Sukry } \\
\text { Pratama }\end{array}$ & 51 & 65 \\
\hline 5 & $\begin{array}{c}\text { Ajeng } \\
\text { Mustika } \\
\text { Ayu } \\
\text { Azzahra }\end{array}$ & 54 & 78 \\
\hline 6 & $\begin{array}{c}\text { Al-Halim } \\
\text { Nuor } \\
\text { Wijaya }\end{array}$ & 54 & 80 \\
\hline 7 & Aloysius A & 87 & 100 \\
\hline 8 & $\begin{array}{c}\text { Alvian } \\
\text { Jalvano }\end{array}$ & 55 & 73 \\
\hline 9 & Amara F & 58 & 79 \\
\hline 10 & Ana S & 57 & 83 \\
\hline 11 & $\begin{array}{c}\text { Ari } \\
\text { Setiawan }\end{array}$ & 63 & 84 \\
\hline Shania & 65 & 89 \\
\hline
\end{tabular}




\begin{tabular}{|c|c|c|c|c|c|c|c|}
\hline 13 & $\begin{array}{c}\text { Bagas } \\
\text { Hermawan }\end{array}$ & 61 & 83 & \multirow[t]{2}{*}{31} & $\begin{array}{c}\text { Irma } \\
\text { Amelia }\end{array}$ & \multirow[t]{2}{*}{62} & \multirow[t]{2}{*}{85} \\
\hline \multirow{2}{*}{14} & Bagus Leo & \multirow{2}{*}{67} & \multirow{2}{*}{78} & & Novianti & & \\
\hline & Putra & & & 32 & Kayla Sofya & 59 & 76 \\
\hline \multirow{2}{*}{15} & Balqis & \multirow{2}{*}{60} & \multirow{2}{*}{82} & \multirow{2}{*}{33} & Kevin & & \\
\hline & Baity & & & & Audresta & 63 & 86 \\
\hline \multirow{2}{*}{16} & Callysta & \multirow{2}{*}{53} & \multirow{2}{*}{77} & \multirow{2}{*}{34} & Kevin & & \\
\hline & Fania & & & & Chandra & 67 & 92 \\
\hline 17 & Cinta Bella & 60 & 85 & \multirow{3}{*}{35} & \multirow{3}{*}{$\begin{array}{l}\text { Khadijah } \\
\text { Amelia } \\
\text { Monica }\end{array}$} & \multirow[b]{3}{*}{53} & \multirow[b]{3}{*}{77} \\
\hline \multirow{3}{*}{18} & Claudia & \multirow{3}{*}{56} & \multirow{3}{*}{77} & & & & \\
\hline & Melah & & & & & & \\
\hline & Situmorang & & & \multirow{2}{*}{36} & \multirow{2}{*}{$\begin{array}{l}\text { M. Arif } \\
\text { Chandra }\end{array}$} & \multirow[b]{2}{*}{61} & \multirow[b]{2}{*}{84} \\
\hline 19 & Damar B & 68 & 90 & & & & \\
\hline \multirow{2}{*}{20} & Darmawan & \multirow{2}{*}{61} & \multirow{2}{*}{76} & \multirow{2}{*}{37} & M. Iqbal & & \\
\hline & Febrio H & & & & & 59 & 87 \\
\hline 21 & Deni Adi P & 57 & 78 & 0 & M.Rizki & & \\
\hline 22 & Dera Adelia & 60 & 83 & 30 & Reza & 85 & 100 \\
\hline 23 & Erin Togi & 44 & 68 & 0 & Maurich & & \\
\hline & Erland & & & 37 & Johan & 63 & 86 \\
\hline 24 & Adha & 60 & 82 & 10 & Melisa Tri & & \\
\hline & Sharendra & & & & Cahyani & 57 & 79 \\
\hline & Fadhel & 60 & O & 41 & Muhamaad & & \\
\hline 25 & Akbar A & & & & Al Fikri & 49 & 70 \\
\hline 26 & Fara Nadila & 55 & 72 & 40 & Muhamma & & \\
\hline & Fitri & & & 42 & d Aldi F & 61 & 83 \\
\hline 27 & Noviana $\mathrm{F}$ & 5 & 19 & & Muhamma & & \\
\hline & Flora Nita & & & 43 & d Gilang & & \\
\hline 20 & Charda & 54 & 00 & & Priadinata & 65 & 89 \\
\hline & Habib & & & & Muhamma & & \\
\hline 29 & Raihan & 59 & 82 & 44 & d Rafi & & \\
\hline & Delu & & & & Hakim & 67 & 93 \\
\hline 30 & Intana D & 67 & 89 & & Niken & & \\
\hline & & & & & Meila & 59 & 80 \\
\hline
\end{tabular}




\begin{tabular}{|c|c|c|c|}
\hline 46 & $\begin{array}{c}\text { Nur Salsa } \\
\text { Bila }\end{array}$ & 54 & 77 \\
\hline 47 & $\begin{array}{c}\text { Rahmat } \\
\text { Kurniawan } \\
\text { Hutasuhut }\end{array}$ & 62 & 86 \\
\hline 48 & Raihan A & 63 & 80 \\
\hline 49 & $\begin{array}{c}\text { Raihan } \\
\text { Bagus } \\
\text { Cahyani }\end{array}$ & 51 & 71 \\
\hline 50 & $\begin{array}{c}\text { Rendy } \\
\text { Hardiansya } \\
\text { h }\end{array}$ & 58 & 80 \\
\hline 51 & $\begin{array}{l}\text { Silpana } \\
\text { Herman }\end{array}$ & 65 & 76 \\
\hline 52 & $\begin{array}{c}\text { Siti } \\
\text { Fatimah }\end{array}$ & 50 & 72 \\
\hline 53 & $\begin{array}{c}\text { Siva Cahya } \\
\mathrm{S}\end{array}$ & 69 & 96 \\
\hline 54 & $\begin{array}{c}\text { Taufik } \\
\text { Hidayat }\end{array}$ & 59 & 82 \\
\hline 55 & Urfatul & 61 & 90 \\
\hline 56 & $\begin{array}{c}\text { Verdian } \\
\text { Rachnadan } \\
\text { i }\end{array}$ & 70 & 91 \\
\hline 57 & Veri Fadli & 59 & 83 \\
\hline 58 & $\begin{array}{l}\text { Vricila } \\
\text { Agatha }\end{array}$ & 49 & 74 \\
\hline 59 & $\begin{array}{c}\text { Yusril } \\
\text { Nurrizki } \\
\text { Firdaus }\end{array}$ & 59 & 80 \\
\hline & Jumlah & 3562 & 4844 \\
\hline & & $\begin{array}{l}\text { Rata- } \\
\text { Rata }\end{array}$ & 82,10 \\
\hline
\end{tabular}

Sumber : Hasil Pos-Test
Berdasarkan hasil post-test pada tabel 5.2 diketahui bahwa rata-rata tingkat pemahaman akhir peserta adalah 82,10\%. Nilai ini masuk dalam kriteria sangat memahami. Jika dibandingkan dengan hasil pre-test berarti secara ratarata telah terjadi peningkatan pemahaman peserta tentang Penguasaan Mengetik Cepat 10 Jari dengan Metode Drill dan pola kolaborasi antar aktor yang terlibat dalam Pelatihan ini. Sebesar 17,90\%. Peserta yang memiliki kriteria belum memahami adalah o\%. Hal ini berarti jika dibandingkan dengan hasil pre-test pemberian materi pelatihan berhasil meningkatkan 100\% pemahaman peserta dari belum memahami ke kriteria yang lebih tinggi (sangat memahami). Namun belum mencapai $100 \%$ peserta yang mencapai kriteria sangat memahami. Sehingga perlu dipertimbangkan untuk menambah pelatihan dengan materi yang sama dan melakukan pendampingan jika ada kegiatan/program yang berkaitan dengan tema pelatihan ini.

\section{KESIMPULAN}

Kesimpulan Pelatihan Penguasaan Mengetik Cepat 10 Jari Dengan Metode Drill Di SMK Negeri 5 Bandar Lampung adalah sebagai berikut : 
1. Rata-rata tingkat pemahaman awal 59 orang peserta Dikalangan Siswa-Siswi Jurusan Multimedia di SMK Negeri 5 Bandar Lampung adalah 59,83\%. Seluruh peserta masuk dalam kriteria cukup memahami tentang Penguasaan Mengetik Cepat 10 Jari dengan Metode Drill dan pola kolaborasi antar aktor yang terlibat dalam pelatihan ini.

2. Upaya yang dilakukan untuk meningkatkan pengetahuan dan pemahaman peserta pelatihan adalah dengan pemberian materi pelatihan tentang Penguasaan Mengetik Cepat 10 Jari dengan Metode Drill dan pola kolaborasi antar aktor yang terlibat dalam pelatihan ini.

3. Rata-rata tingkat pemahaman akhir peserta adalah 82,10\% dan nilai ini masuk dalam kriteria sangat memahami. Pemberian materi pelatihan berhasil meningkatkan 100\% pemahaman peserta.

\section{UCAPAN TERIMA KASIH}

Tim kegiatan pengabdian pada masyarakat mengucapkan terima kasih kepada Bapak Drs.Ifraim Aziz,M.M. selaku Kepala Sekolah SMK Negeri 5 Bandar Lampung yang telah memberikan izin untuk dapat melaksanakan kegiatan ini dengan baik. Dan ucapan terima kasih sebesar-besarnya kepada LPPM Universitas Lampung yang telah mendanai kegiatan ini.

\section{DAFTAR PUSTAKA}

Anita Desiani. (2020). Pemanfaatan Ms.Excel untuk Pembukuan Keuangan UMKM Desa Bangsal Kecamatan Pampangan. Dinamisia : Jurnal Pengabdian Kepada Masyarakat, 5(1), 224-230. https://doi.org/10.31849/dinamisia .$v 5 \mathrm{i1} .4464$

Erpidawati, \& Novelti. (2021). Pelatihan Pemanfaatan Teknologi Google Drive dan Blogs bagi Pengawas Sekolah Dasar. Dinamisia: Jurnal Pengabdian Kepada Masyarakat, 5(2), 330-334. https://doi.org/10.31849/dinamisia .v5i2.5348

Fadilla Oktaviana, \& Ida Nuraida. (2021). Teknologi Informasi Desa, Upaya Meningkatkan Partisipasi Dan Keterampilan Masyarakat Dalam Pembangunan Desa. Dinamisia : Jurnal Pengabdian Kepada Masyarakat, 5(2), 269-275. https://doi.org/10.31849/dinamisia .$v 5 i 2.4567$

Junaidi, A., Utami, Y. T., Sakethi, D., \& Pribadi, I. A. (2020). Pelatihan 
mengetik cepat dengan metode kanang di desa tambah dadi, kecamatan Purbolinggo, Lampung Timur. Jurnal Pengabdian Kepada Masyarakat (JPKM) TABIKPUN, 1(1), $31-38$. https://doi.org/10.2396o/jpkmt.v1i 1.5

Khoiriyah, K., \& Puspasari, D. (2021).

Penerapan Metode Pembelajaran

Drill melalui Typing Master untuk Meningkatkan Keterampilan

Mengetik 10 Jari pada Mata Pelajaran Teknologi Perkantoran di SMK Krian 2 Sidoarjo. Jurnal Edukasi, $\quad 8(1), \quad 6$. https://doi.org/10.19184/jukasi.v8i 1.23967

Media, P., Typing, P., \& Terhadap, M. (2017). Pengaruh Disiplin Belajar, Fasilitas Belajar Dan Penggunaan Media Pembelajaran Typing Master Terhadap Kecepatan Mengetik 10 Jari Buta Pada Siswa Kelas X Smk Pgri 1 Mejobo Kudus Program Keahlian Administrasi Perkantoran. Economic Education Analysis Journal, 6(1), 150-160.

Ninghardjanti, P., \& Yuwantiningsih, A. (2018). Peningkatan kecepatan mengetik 10 jari melalui penerapan metode drill dan resitasi (pada peserta didik kelas X AP 1 SMK Negeri 1 Surakarta tahun pelajaran
2018 / 2019). Prosiding Seminar Nasional Pendidikan Administrasi Perkantoran (SNPAP) 2018, 7-13. https://jurnal.uns.ac.id/snpap/arti cle/view/27870

Permata, E., M, Y. R. D., Irwanto, \& Fatkhurrokhman, M. (2021). Pelatihan Komputer Microsoft Office dan Media Pembelajaran Animasi untuk Meningkatkan Kompetensi Guru SDIT Al Muhajirin. Dinamisia : Jurnal Pengabdian Kepada Masyarakat, 5(2), 413-420.

https://doi.org/10.31849/dinamisia . $\mathrm{v} 5 \mathrm{i} 2.5265$

R. A. N., Ike Wardani, S., \& Widayani, A. (2020). Pemanfaatan Digital Marketing sebagai Sarana Komersialisasi Produk Kampung Batik Kembang Turi Blitar. Dinamisia: Jurnal Pengabdian Kepada Masyarakat, 5(1), 253-261. https://doi.org/10.31849/dinamisia .$v 5 \mathrm{i} 2.4157$

S., Syahri, M., Ernaningsih, D. N., Inawati, \& Dewi, A. N. (2021). Pelatihan dan Pendampingan Manajemen Perpustakaan Sekolah Berbasis Teknologi Informasi. Dinamisia : Jurnal Pengabdian Kepada Masyarakat, 5(2), 427-436. https://doi.org/10.31849/dinamisia .v5i2.5260 
Sesunan, F., Abdurrahman, Nurulsari, N.,

\& Maulina, H. (2021). Penyusunan

Unit Pembelajaran Inquiry Based

Learning Berorientasi Kemampuan

Abad 21. Dinamisia : Jurnal

Pengabdian Kepada Masyarakat, 5(2), 312-319.

https://doi.org/10.31849/dinamisia .v5i2.4377

Suntoro. (2020). Pelatihan Pembuatan

Blog Pembelajaran Bagi Guru

Sekolah Dasar Punna Karya

Kabupaten Tangerang. Dinamisia :

Jurnal Pengabdian Kepada

Masyarakat, 5(1), 47-53.

https://doi.org/10.31849/dinamisia

. $\mathrm{V} 5 \mathrm{i1} .4569$

Suripto, S. (2020). Pelatihan Literasi

Keuangan Produk Di Kelurahan.

DHARMA: Jurnal Pengabdian

Masyarakat, 6788, 14-22.

http://jurnal.upnyk.ac.id/index.ph

$\mathrm{p} / \mathrm{dlppm} /$ article/view/4037

Tjahjono, B. (2016). Pelatihan Mengetik

Sebagai Sarana Penerapan Karakter

Dan Skill Pada Sd/Smp Birrul

Walidain. Jurnal Pengabdian

Masyarakat AbdiMas, 2(1). 